\title{
Inbreeding as a Cause of Congenital Hydrocephalus
}

\author{
Tanya T Kitova ${ }^{1}$, Anastasia V Bailey ${ }^{2}$
}

\begin{abstract}
Aim: The aim of the study was to determine the role of inbreeding in occurrence of lethal congenital hydrocephalus (LCH) and congenital abnormalities associated with it.

Materials and methods: There was an examination of 182 fetuses born with LCH, out of which 69 were diagnosed with isolated and 113 fetuses were diagnosed with associated hydrocephalus resulting in $38 \%$ and $62 \%$ occurrences, respectively. All the fetuses were the result of spontaneous abortions, stillbirths, neonatal deaths and the pregnancy terminations due to medical reasons. The fetal autopsy was performed immediately after the fetal expulsion. The brain examination was performed after being preserved in $10 \%$ formalin solution for the period of 6 months. Measurements were taken on the ventricles in their central parts. Ventricles with the enlargements over $10 \mathrm{~mm}$ were determined as hydrocephalus and severe ventriculomegaly if the ventricular dimensions were over $15 \mathrm{~mm}$.

Results: Lethal congenital hydrocephalus associated with were the presence of previous pregnancies with inbreeding and malformations [OR $=$ $7.309 \mathrm{Cl} 95 \%$ (1.806-29.584)]; the maternal age over 40 and the third-degree inbreeding in fetus [OR $=18.500 \mathrm{Cl}$ 95\% (1.410-638.150)]; agenesis of the corpus callosum in fetuses born from mothers in close relative marriages [OR $=30.000 \mathrm{Cl} 95 \%(1.410-638.150)]$; aqueductal stenosis [OR $=9.867$ Cl 95\% (1.328-73.296)]; skeletal dysplasia [OR = 6.727 Cl 95\% (1.203-37.609)]; and Dandy-Walker syndrome [OR =6.250 Cl 95\% (0.803-48.671)]. Conclusion: The obtained results unambiguously prove the importance and significance of inbreeding as a risk factor of LCH appearance and its increase in association with other risk factors which should be taken into consideration when observing such pregnancies.

Clinical significance: Lethal congenital hydrocephalus is the result of a significant number of risk factors and is often associated with other malformations. Currently, prenatal ultrasound is able to visualize ventriculomegaly. It is important to gather information about the previous pregnancies and the type of marriage among close relatives. In case of ventriculomegaly it is imperative to carry out MRI and genetic testing that can provide additional information. In the case of medical abortion, stillbirth or neonatal death, a fetopathological study must be carried out which enriches our knowledge of malformations, complements and directs the ultrasound examination, modifies genetic counseling and determines the behavior to be followed when taking responsibility for a new, subsequent pregnancy.

Keywords: Congenital anomalies, Hydrocephalus, Inbreeding, Prenatal diagnosis, Risk factors, Ultrasound.

International Journal of Infertility and Fetal Medicine (2019): 10.5005/jp-journals-10016-1177
\end{abstract}

\section{INTRODUCTION}

Consanguineous or close relative marriages are a very rare social phenomenon in highly developed countries of Europe, as well as in Latin America and Western Asia. On the contrary, cousin marriages and marriages between other relatives in most Muslim countries from Morocco to Pakistan are a common practice with a wide range of $20-80 \%{ }^{1,2}$ Worldwide, about $6.5 \%$ of the total number of couples are in close relative relationships. The frequency of consanguineous marriages varies widely depending on the culture, traditions, and the corresponding/relating civil laws. ${ }^{3}$

It is a well-known fact that babies born in consanguineous marriages have a much higher risk of developing rare recessive syndromes and congenital malformations. ${ }^{4,5}$

Rittler et al. state that inbreeding is, to a great extent, associated with three types of congenital malformations, mainly, hydrocephalus, postaxial ulnar polydactyly, labial or palatal bilateral cleft. ${ }^{6}$ The frequency of cases of congenital hydrocephalus, depending on clinical criteria used for its differentiation, varies from 1 to 32 per 10,000 newborn babies. ${ }^{7}$ Serious malformations associated with congenital hydrocephalus are observed in almost $50 \%$ of the cases and has become the cause of fetal death, spontaneous abortion, or neonatal death. Therefore, the congenital hydrocephalus associated malformations can be defined as lethal and are not a subject to successful treatment. In order to reduce the risk factor the common recommendation is to terminate the pregnancy due to medical reasons. ${ }^{8}$

The aim of the study was to determine the role of inbreeding in occurrence of $\mathrm{LCH}$ and congenital abnormalities associated with it.

\footnotetext{
1,2 Department of Anatomy, Histology and Embryology, Medical University of Plovdiv, Plovdiv, Bulgaria

Corresponding Author: Tanya T Kitova, Department of Anatomy, Histology and Embryology, Medical University, Plovdiv, Bulgaria, Phone: +359 887855857, e-mail: tanyakitova@yahoo.com

How to cite this article: Kitova TT, Bailey AV. Inbreeding as a Cause of Congenital Hydrocephalus. Int J Infertil Fetal Med 2019;10(1):4-7.

Source of support: Nil

Conflict of interest: None
}

\section{Materials and Methods}

There was an examination of 182 fetuses born with $\mathrm{LCH}$, out of which 69 were diagnosed with isolated and 113 fetuses were diagnosed with associated hydrocephalus resulting in $38 \%$ and $62 \%$ occurrences, respectively. There were 172 fetuses obtained from the 21,316 births during a 3-year fetopathological examination (from 2006 to 2009) which took place in Embryo-Fetopathological Clinics at the Centre for Maternity and Neonatology, Tunis, Tunisia. Another 10 fetuses with LCH were recorded from a total of 2,104 births in the Obstetrics and Gynaecology Clinic at St. George EAD University Hospital, Plovdiv, in the year 2016.

All the fetuses were the result of spontaneous abortions, stillbirths, neonatal deaths and the pregnancy terminations due to medical reasons. The data on the mothers and fetuses was acquired from their obstetric history. 


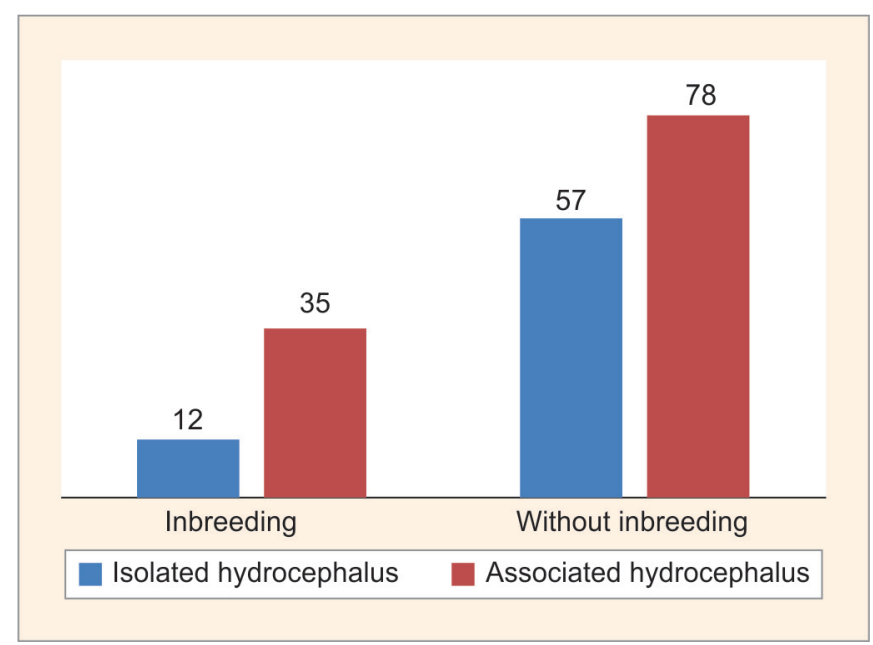

Fig. 1: Lethal congenital hydrocephalus distribution by data for inbreeding fetuses

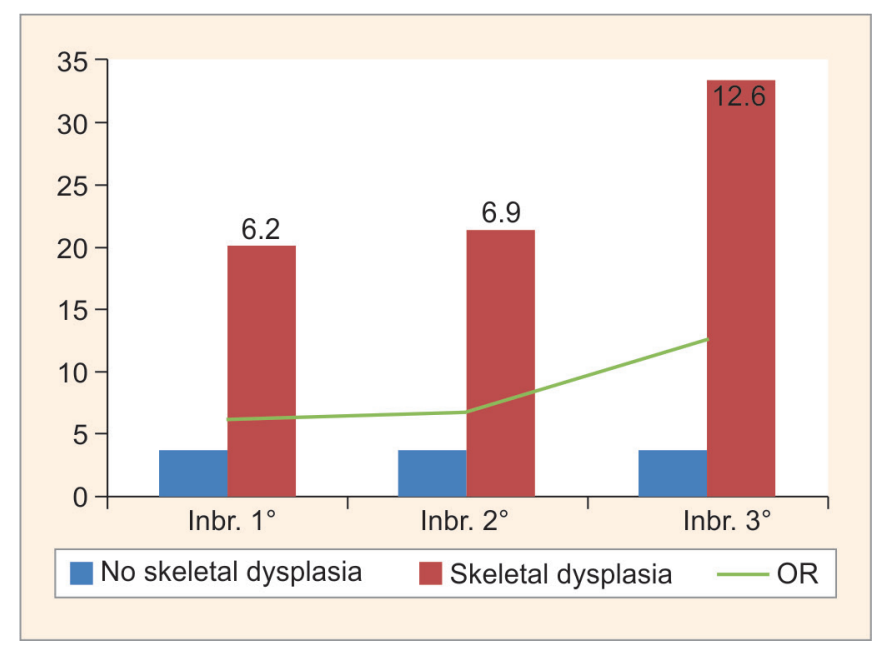

Fig. 3: Inbreeding, skeletal dysplasia, and lethal congenital hydrocephalus

The fetal autopsy was performed immediately after the fetal expulsion followed by the macro- and microexaminations carried out with the parental permission. The autopsy procedure included the observation of the fetuses as whole, their body surface cavities and collecting the biometric data in situ. The brain examination was performed after being preserved in $10 \%$ formalin solution for the period of 6 months. Measurements were taken on the ventricles in their central parts. Ventricles with the enlargements over $10 \mathrm{~mm}$ were determined as hydrocephalus and severe ventriculomegaly if the ventricular dimensions were over $15 \mathrm{~mm} .{ }^{9}$ Each macroexamination was accompanied by a specimen being obtained for further histological examination from the area of brain cortex, brainstem, choroid plexus and meninges.

For the data interpretation SPSS version 19 was used. A descriptive analysis and $\mathrm{a} \chi^{2}$ analysis were applied.

\section{Results}

Anamnestic data for inbreeding in the two groups were determined in 47 cases (25.8\%), 14 cases (29.8\%) specified with the first degree, 9 cases (19.1\%) with the second degree and 24 cases (51.1\%) with

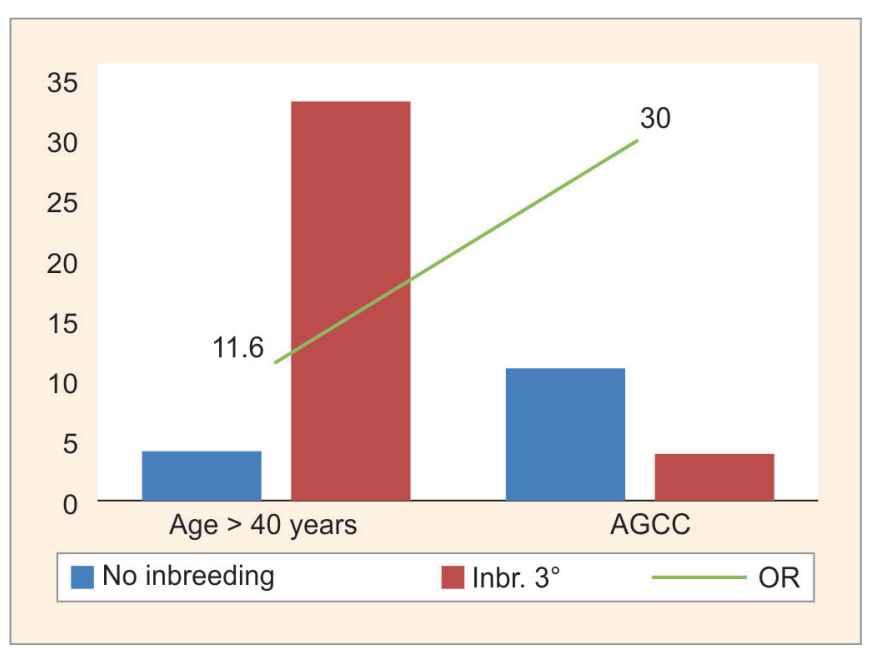

Fig. 2: Inbreeding, mother's age, agenesis of corpus callosum and lethal congenital hydrocephalus. AGCC, agenesis of corpus callosum

the third degree. Inbreeding seemed to be more of the etiologic factor in fetuses as they occurred in $31 \%$ of the cases (Fig. 1). Every diagnosis of hydrocephalus with other anomalies in all other organs and systems is regarded as associated hydrocephalus.

\section{Maternal Age and Agenesis of the Corpus Callosum}

Our research has established that there is a significant correlation between the appearance of $\mathrm{LCH}$ and the maternal age of over 40 as well as third-degree inbreeding, with a serious risk [OR $=11.667$ Cl 95\% (0.924-147.298)] (Fig. 2).

The fetus from a mother being a close relative marriage is at a 6 times increased risk of developing hydrocephalus associated with the agenesis of the corpus callosum leading to the fetal third-grade inbreeding, and the risk is significantly high [OR $=30.000 \mathrm{Cl} 95 \%$ (1.410-638.150)] (Fig. 2).

\section{Skeletal Dysplasia}

Skeletal dysplasia is highly associated with LCH in the presence of consanguineous marriage (Fig. 3). The share of LCH with the combination of bone dysplasia and inbreeding of the first and second degree is 5 times higher [OR $=9.867 \mathrm{Cl} 95 \%$ (1.236-38.610)] and 9 times higher if bone dysplasia is combined with the thirddegree inbreeding [OR $=9.867 \mathrm{Cl} 95 \%(0.883-181.687)]$.

\section{Previous Births of Babies with Congenital Birth Defects, Aqueductal Stenosis, and Dandy-Walker Malformation}

The important indicator of the development of $\mathrm{LCH}$ is the presence of previous births of babies with congenital birth defects, especially of those born in consanguine marriages. The appearance of LCH in those cases is almost fourfold, with quite a high risk $[\mathrm{OR}=4.410 \mathrm{Cl}$ 95\% (1.443-13.482)] (Table 1).

Aqueductal stenosis is significantly associated with inbreeding and is a cause of congenital hydrocephalus resulting from consanguineous marriage (Table 1). The share of LCH with aqueductal stenosis, as a precursor, and the second-degree inbreeding is about 7 times higher, with quite a significant risk [OR $=9.867 \mathrm{Cl}$ 95\% (1.328-73.296)] (Table 1).

Dandy-Walker malformation in association with inbreeding is closely connected with LCH (Table 1). It is found to be 5.5 times 
Inbreeding as a Cause of Congenital Hydrocephalus

Table 1: Inbreeding, malformations, aqueductal stenosis, Dandy-Walker malformation, and lethal congenital hydrocephalus

\begin{tabular}{|c|c|c|c|c|c|c|c|c|c|c|c|}
\hline \multirow[b]{2}{*}{ Indicator } & \multirow[b]{2}{*}{ Groups } & \multicolumn{2}{|c|}{$\begin{array}{c}\text { Without } \\
\text { malformation }\end{array}$} & \multicolumn{2}{|c|}{$\begin{array}{c}\text { With } \\
\text { malformation }\end{array}$} & \multicolumn{2}{|r|}{ Total } & \multirow[b]{2}{*}{$\chi^{2}$} & \multirow[b]{2}{*}{$p$} & \multirow[b]{2}{*}{ Fisher } & \multirow[b]{2}{*}{ ORCI } \\
\hline & & No & $\%$ & No & $\%$ & No & $\%$ & & & & \\
\hline \multirow[t]{3}{*}{ Inbreeding } & No & 129 & 95.6 & 6 & 4.4 & 135 & 100.0 & \multirow[t]{3}{*}{7.766} & \multirow[t]{3}{*}{0.005} & \multirow[t]{3}{*}{0.010} & \multirow[t]{3}{*}{$4.410(1.443-13)$} \\
\hline & There is & 39 & 83.0 & 8 & 17 & 47 & 100.0 & & & & \\
\hline & Total & 168 & 92.3 & 14 & 7.7 & 182 & 100.0 & & & & \\
\hline & & \multicolumn{2}{|c|}{ Without AS } & \multicolumn{2}{|c|}{ With AS } & \multicolumn{2}{|c|}{ Total } & \multirow[b]{2}{*}{$\chi^{2}$} & \multirow[b]{2}{*}{$p$} & \multirow[b]{2}{*}{ Fisher } & \multirow[b]{2}{*}{ ORCI } \\
\hline Indicator & Groups & No & $\%$ & No & $\%$ & No & $\%$ & & & & \\
\hline \multirow{3}{*}{$\begin{array}{l}\text { Inbreeding II } \\
\text { degree }\end{array}$} & No & 74 & 96.1 & 3 & 3.9 & 77 & 100.0 & 6.979 & 0.008 & 0.044 & $9.867(1.328-73.296)$ \\
\hline & There is & 5 & 71.4 & 2 & 28.6 & 7 & 100.0 & & & & \\
\hline & Total & 79 & 94.0 & 5 & 6.0 & 84 & \multicolumn{2}{|l|}{100.0} & & & \\
\hline \multirow[b]{2}{*}{ Indicator } & \multirow[b]{2}{*}{ Groups } & \multicolumn{2}{|c|}{ Without DWM } & \multicolumn{2}{|c|}{ With DWM } & \multicolumn{2}{|c|}{ Total } & \multirow[b]{2}{*}{$\chi^{2}$} & & \multirow[b]{2}{*}{ Fisher } & \multirow[b]{2}{*}{$\mathrm{ORCl}$} \\
\hline & & No & $\%$ & No & $\%$ & No & $\%$ & & $p$ & & \\
\hline \multirow{3}{*}{$\begin{array}{l}\text { Indicators I } \\
\text { degree }\end{array}$} & No & 77 & 97.5 & 2 & 2.5 & 79 & 100.0 & \multirow[t]{3}{*}{3.992} & 0.046 & 0.106 & $6.417(0.824-49.953)$ \\
\hline & There is & 12 & 85.7 & 2 & 14.3 & 14 & 100.0 & & & & \\
\hline & Total & 89 & 95.7 & 4 & 4.3 & 93 & 100.0 & & & & \\
\hline
\end{tabular}

No, number; $\mathrm{Cl}$, confidence intervals; OR, odds ratio; $+p$, sig; $\mathrm{HC}$; $\mathrm{AS}$, aqueductal stenosis; DWM, Dandy-Walker malformation

more frequent when Dandy-Walker malformation and first-degree inbreeding are combined [OR $=6.417 \mathrm{Cl} 95 \%(0.824-49.953)]$.

\section{Discussion}

In their research Rittler et al. established significant association between consanguineous marriages and hydrocephalus, postaxial ulnar polydactyly, labial or palatal bilateral cleft. ${ }^{6}$ The similar results were obtained by Stoll et al. who established the statistical reliability in the association between inbreeding and congenital hydrocephalus. $^{10}$

Rajab et al. carried out a promising study in which they compared the data of children born in consanguineous families with healthy children born in the same type of families. ${ }^{11}$ All the 11 cases of the congenital hydrocephalus occurred in consanguineous families (45\% in first-cousin marriages, $27 \%$ in second-cousin marriages, and $28 \%$ in more distant relative marriages).

Murshid et al., during their epidemiological study in Saudi Arabia of congenital hydrocephalus and associated with its occurrence factors determined that, despite the large number of consanguineous families (73\%), inbreeding was not found to be a significant risk factor in comparison to the control group (63\%). ${ }^{12}$

Our research has proved the link between consanguineous marriages and occurrence of congenital disorders which strengthens with the presence of specific circumstances - this fact could not be found in any available literature. The nonparametric analysis applied to the obtained data established that $\mathrm{LCH}$ is associated with

- The presence of previous pregnancies with inbreeding and malformations [OR $=7.309 \mathrm{Cl} 95 \%$ (1.806-29.584)]

- The maternal age over 40 and the third-degree inbreeding in fetus [OR $=18.500 \mathrm{Cl} 95 \%$ (1.410-638.150)]

- Agenesis of the corpus callosum in fetuses born from mothers in close relative marriages $[\mathrm{OR}=30.000 \mathrm{Cl} 95 \%(1.410-638.150)]$
On the other hand, our research established the significance of inbreeding in occurrence of LCH associated with other certain abnormalities. The presence of inbreeding of first and third degrees greatly increases the risk of LCH associated with (a) aqueductal stenosis [OR $=9.867 \mathrm{Cl} 95 \%$ (1.328-73.296)], (b) skeletal dysplasia $[\mathrm{OR}=6.727 \mathrm{Cl} 95 \%$ (1.203-37.609)], and (c) Dandy-Walker syndrome $[\mathrm{OR}=6.250 \mathrm{Cl} 95 \%(0.803-48.671)]$.

\section{Conclusion}

The obtained results unambiguously prove the importance and significance of inbreeding as a risk factor of LCH appearance and its increase in association with other risk factors which should be taken into consideration when observing such pregnancies.

\section{References}

1. Bittles $\mathrm{AH}$. Consanguinity and its relevance to clinical genetics. Clin Genet 2001;60(2):89-98. DOI: 10.1034/j.1399-0004.2001. 600201.x.

2. el-Hazmi MA, al-Swailem AR, Warsy AS, et al. Consanguinity among the Saudi Arabian population. J Med Genet 1995;32(8):623-626. DOI: 10.1136/jmg.32.8.623.

3. Bage NN, Rao S. Is consanguineous marriage responsible for congenital cardiac and extra-cardiac anomalies? J Evolution Med Dent Sci 2016;5(19):930-932. DOI: 10.14260/jemds/2016/216.

4. Harlap S, Kleinhaus K, Perrin MC, et al. Consanguinity and birth defects in the jerusalem perinatal study cohort. Hum Hered 2008;66(3): 180-189. DOI: $10.1159 / 000133837$.

5. Porto R, Reis FP, da Cunha Oliveira CC, et al. Prevalence and factors associated at presence of central nervous system congenital malformations. Br J Med Med Res 2015;6(10):956-964. DOI: 10.9734/ BJMMR/2015/14642.

6. Rittler M, Liascovich R, López-Camelo J, et al. Parental consanguinity in specific types of congenital anomalies. Am J Med Genet 2001;102(1):36-43. DOI: 10.1002/1096-8628(20010722)102:1<36::AIDAJMG1394>3.0.CO;2-M. 
7. Jeng S, Gupta N, Wrensch M, et al. Prevalence of congenital hydrocephalus in California, 1991-2000. Pediatr Neurol 2011;45(2): 67-71. DOI: 10.1016/j.pediatrneurol.2011.03.009.

8. Benute GRG, Nomura RMY, Liao AW, et al. Feelings of women regarding end-of-life decision making after ultrasound diagnosis of a lethal fetal malformation. Midwifery 2012;28(4):472-475. DOI: 10.1016/j.midw.2011.06.011.

9. Coady AM. Cranial abnormalities. In: Coady AM, Bower S, ed. Twining's Textbook of Fetal Abnormalities, 3rd ed., Churchill Livingstone; 2015. p. 223.
10. Stoll C, Alembik Y, Dott B, et al. An epidemiologic study of environmental and genetic factors in congenital hydrocephalus. Eur J Epidemiol 1992;8(6):797-803. DOI: 10.1007/BF001 45322.

11. Rajab A, Vaishnav A, Freeman NV, et al. Neural tube defects and congenital hydrocephalus in the Sultanate of Oman. J Trop Pediatr 1998;44(5):300-303. DOI: 10.1093/tropej/44.5.300.

12. Murshid WR, Jarallah JS, Dad MI. Epidemiology of infantile hydrocephalus in Saudi Arabia: birth prevalence and associated factors. Pediatr Neurosurg 2000;32(3):119-123. DOI: 10.1159/000028915. 